OPEN ACCESS

Edited by:

Elena Kovtun

National University of Life and

Environmental Sciences of

Ukraine, Ukraine

Reviewed by:

Heru Irianto,

Sebelas Maret University, Indonesia Alessio Cappelli,

University of Florence, Italy

${ }^{*}$ Correspondence:

Danka Moravčíková

danka.moravcikova@uniag.sk

Specialty section:

This article was submitted to

Sustainable Food Processing,

a section of the journal

Frontiers in Sustainable Food Systems

Received: 04 June 2021

Accepted: 11 August 2021

Published: 03 September 2021

Citation:

Moravčiková D, Tkáč F and

Mušinská K (2021) Selected Aspects

and Determinants of the Slovak

Agro-Food Companies

Innovativeness.

Front. Sustain. Food Syst. 5:720730.

doi: 10.3389/fsufs. 2021.720730

\section{Selected Aspects and Determinants of the Slovak Agro-Food Companies' Innovativeness}

\author{
Danka Moravčíková ${ }^{1 *}$, Filip Tkáč ${ }^{1}$ and Kristína Mušinská ${ }^{2}$ \\ ${ }^{1}$ Department of Social Sciences, Faculty of Economics and Management, Slovak University of Agriculture in Nitra, Nitra, \\ Slovakia, ${ }^{2}$ Department of Marketing and Trade, Faculty of Economics and Management, Slovak University of Agriculture in \\ Nitra, Nitra, Slovakia
}

Sustainability and innovation are key elements of the economic growth and productivity in the contemporary era. The willingness, ability, and capacity to innovate is a strategic tool for the Slovak agro-food companies that want to maintain and/or to improve their market. The aim of this paper is to discuss the selected aspects and determinants of innovative performance of the Slovak agro-food companies and point out key areas and types in innovations, problems influencing their implementation, and assessing their success. The issue of innovation and the "new" role of the agro-food sector have become crucial in the context of transition of the Slovak economy toward more sustainable approaches. Therefore they have become important topics of both scientific research and policy agendas. Using a case study method, a questionnaire survey among 99 agro-food companies in Slovakia was carried out to obtain empirical data about the way how they manage, implement and evaluate the innovations. The study outlined the selected aspects and key determinants which affect the motivation of agro-food companies to innovate as well as selected factors influencing the processes of implementation and management of innovation. The research findings also point out that substantial changes will be required in regulation and support of innovations in the agro-food sector in Slovakia. The study could contribute to help the agro-food companies' managers to improve the innovation activities and competitiveness of their companies, and it would be also helpful for public administration in the development of policies and instruments supporting innovations in the agro-food sector.

Keywords: agro-food sector, innovation, innovative performance, value chains, sustainability

\section{INTRODUCTION}

The issue of innovation in the agro-food sector is very broad and involves the primary, secondary, and tertiary sectors. The potential for innovation is now seen as an essential part of the contemporary life (Cappelli and Cini, 2021). Innovation potential can be characterized as a new state of play, accompanied by many changes, challenges and opportunities (Cappelli et al., 2020b). The concept of innovation cannot be reduced only to technological aspect, it includes non-technological aspects, human capital, marketing, organization structure, and many other related aspects. To date, one of the most used definitions of innovation which gives a more precise formulation for use by businesses is found in the Oslo Manual 2018, 
which distinguishes between innovation as an outcome (innovation) and the activities by which innovations come out (innovation activities). This updated version (OECD/EUROSTAT, 2018) defines an innovation as "a new or improved product or process (or combination thereof) that differs significantly from the unit's previous products or processes and that has been made available to potential users (product) or brought into use by the unit (process)."

Implementation of innovations supported by knowledge and technology transfer across agro-food related sectors and food value chains has become a necessity for those stakeholders that search for new production and business opportunities. New processes, influenced by modern consumer lifestyles, socio-economic megatrends, business needs, and advanced technologies, create new contexts for the development path and challenges also for policy makers (Cavicchi and Stancova, 2016). These tendencies have resulted in identification of agro-food sector as one of the smart specialization priorities in many European countries, and in pointing out the importance of stronger collaboration among different actors at different agrofood value chain stages including $\mathrm{R} \& \mathrm{D}$ institutions. On the one hand, the agro-food sector is usually understood as one of the most important sectors in the European context, and as a sector characterized by strong competition between firms, on the other hand, it is a sector with low levels of R\&D intensity (Hirsch and Gschwandtner, 2013; Zouaghi and Sánchez, 2016). Therefore, innovations which respond to customer demands and sustainability challenges seem to be the important tool for increasing the competitiveness of agro-food companies and for improving the profitability of innovations (Vanhonacker et al., 2013; Cappelli and Cini, 2021). Consumer awareness toward innovative marketing strategies, methods for ensuring food safety and quality, implementation of environmental friendly technologies etc. is a key factor for wider acceptance of innovations.

The agro-food industry groups a set of heterogeneous activities, ranging from the transformation of animal and vegetable raw materials to the production of sophisticated food products, and it also has a direct impact on the environment, playing an essential role in the sustainable management of natural sources and in the adaption and mitigation of climate change effects (Corchuelo Martínez-Azúa et al., 2020). When defining and analyzing innovation in the agro-food domain, different dimensions should be taken into account because innovations could include e.g. new types of fodder, new feeding systems, new types of packaging, conservation, new additives and flavors, new types of logistics etc. (Christensen, 2008; Finco et al., 2018). Innovation potential of the firm represents its overall capacity which is directed toward a successful realization of the entrepreneurial vision. The emphasis is on the quality of potential, which creates both the precondition and the possibility of designing and, above all, implementing the innovation strategy. The innovation potential is thus characterized as a company's capability, which ensures business development and implementation of innovation (Drucker, 1985; Pittner and Švejda, 2004). Innovation potential is the driving force of a company that delivers economic growth, economic development, and increases the competitiveness of the company (Jongen and Meulenberg, 2005). The quality of innovation potential is determined by knowledge of the innovative needs of a company, the existence of innovative opportunities, the level of innovation culture of the company, motivation of workers to innovate, willingness for cooperation, openness, and modernization. Generally, innovation in agro-food sector follow Deming approach (PDCA) (Cappelli et al., 2019). As a result, innovations are usually firstly developed by $R \& D$ activities at pilot or laboratory scale (Cappelli et al., 2019, 2020a). Successively, according to several factors like operation area, funding opportunities, networks, size, age and target market of the company, these innovations were modified and released in the market.

The term "agro-food sector" is more commonly used in research and industry rather than the term "agricultural sector" because of the limited amount of available regional statistical data for the agricultural sector (European Commission, 2007). In the European Union, the food and drink industry represents the largest manufacturing sector in terms of turnover, value added and employment-it employs 4.82 million people, generates a turnover of $€ 1.2$ trillion and $€ 266$ billion in value added (Food Drink Europe, 2020). The EU extensive food supply chain, from agriculture and the input industry to food and drink services, employs 34 million people (Food Drink Europe, 2020). The agriculture sector is comprised of 10,330,000 companies and the food and drink sector comprises 291,000 companies of different sizes, a total of $99 \%$ of them are small and mediumsized firms (Food Drink Europe, 2020). The food supply chain is a major source of jobs and growth, particularly in rural areas (Food Drink Europe, 2020). Small and medium-sized firms are closely linked to local producers and they rely on them to source competitively priced raw materials of appropriate quantity and quality. They are also diverse regarding innovation, from consumer research, improving efficiency to making production more environmentally sustainable, technology and digitalization are key components of small and medium-sized firms growth. Apart from infrastructure and available financial resources, key factors influencing innovation potential of small and medium-sized firms include intellectual factors (e.g., patents, licenses, inventions) and quality of human capital (qualification, expertise, skills).

The COVID-19 pandemic has affected every sector of the economy. The pandemic induced shock is an important test of the resiliency of the economies of Central and Eastern Europe. Despite its steady growth and relative resilience, the agro-food industry has also been impacted and it also accelerated certain trends that have already been developing within the agro-food industry. According to the EIT Food report "Food Foresight: Impact of COVID-19 on the agro-food sector in Central and Eastern Europe" (Maciborski et al., 2021), several historical patterns of development from the last decade, which could stifle growth during economic shocks, have been identified. Agro-food sector in Slovakia is facing a lot of problems as well as a lot of challenges. The sector has been undergoing structural transformation and it suffers from low productivity and diversity. The companies operating in the agro-food sector 
show signs of low productivity, innovativeness, and poor adaptation to the newest technologies (Maciborski et al., 2021; National Agricultural Food Centre Slovakia Research Institute of Agricultural Food Economics, 2021). Therefore, the sector has to manage current challenges and future opportunities for sustainable development within the context of new paradigms of the European Green Deal.

Generally, Slovakia as a country belongs to the group of socalled "moderate innovators" and over time, its performance has increased relative to that of the EU in 2012 entrepreneurship (European Commission, 2020). Slovakia shows the highest positive difference to the $\mathrm{EU}$ in total entrepreneurial activity, value-added share foreign-controlled enterprises, and average annual change in GDP, and the biggest negative difference in top $\mathrm{R} \& \mathrm{D}$ spending enterprises, GDP per capita and buyer sophistication entrepreneurship (European Commission, 2020). Overall, Slovakia's lowest indicator scores include venture capital expenditure, $\mathrm{R} \& \mathrm{D}$ expenditures in the business sector, lifelong learning, and opportunity-driven entrepreneurship (European Commission, 2020). Based on the described context and the above mentioned facts, it is important to point out and to discuss selected factors which determine the level of innovativeness of the Slovak agro-food companies and to highlight the challenges and perspectives for improvement. Since none of the economic sectors operates independently, it is possible to assume that the agro-food sector in Slovakia is a bit different in terms of innovativeness than the whole national economy. In fact, there are some statistical data about the innovation activity of enterprises in the Slovak Republic from the period 2014-2016 (Statistical Office of the Slovak Republic, 2018) and data from an online survey realized among 144 small and medium-sized firms in 2020 (Slovak Business Agency, 2020) indicating lower innovativeness of agro-food enterprises, as well as a lack of awareness about innovations (agro-food small and medium-sized firms were represented in the online survey sample by the lowest share-only $1.4 \%$ ).

Other innovation audits and analyses of innovation demands realized in Slovakia pointed out also similar findings and conclusions (Fáziková and Mariš, 2010; Balog and Kol, 2013). They showed that the majority of agricultural companies considered innovation as an essential issue in their strategical management, but at the same time they faced a huge financial and materials supply difficulties and, additionally, problems with human potential during the implementation process. Innovations were usually represented by the adaptation of external ideas to internal conditions, particularly in case of small and medium-sized firms which did not have their own development capacities. Most of the agro-food companies declared that they were not enough prepared for technology transfer and cooperation with universities and R\&D institutions. The mechanisms and instruments for external support of innovation activities were mostly used for improving the infrastructure of agricultural enterprises. Nevertheless, there has been a deficit of empirical data from the agro-food sector. Therefore, the motivation of the authors for addressing this topic has been twofold. Firstly, the issue of innovation in various economic sectors has become a leading agenda in both political and research domains. Secondly, although the importance of the agro-food sector for further sustainable development of the Slovak society is indisputable, its societal status is low and its position within national political priorities is also underestimated. Obtaining empirical data directly from companies and information about the way how they deal with the innovation issue could help to understand better the phenomenon of innovativeness of the Slovak agro-food sector in the context of the European and national innovation policies and strategies.

\section{MATERIALS AND METHODS}

\section{Respondents}

Respondents were interviewed personally or contacted, using phone or online platforms. The respondents contacts were obtained from the Slovak Agriculture and Food Chamber, the Rural Development Agency, and the Agricultural Paying Agency. We did not aim to recruit a representative sample of agrofood companies, therefore we created an own database of agrofood companies including face-to-face contacted entities which participated in international and national agricultural and food exhibitions. The research intent was to collect quality data via personal and multiple communication with representatives of selected agro-food companies.

Thorough identification of relevant representatives of the business sector in the field of agriculture and food industry it was important to group a balanced sample from the point of view of factors which could influence the level of the company's innovativeness. When selecting and segmenting agro-food companies, several important aspects were taken into account. Firstly, the territorial aspect, because of different regional conditions and innovation context, therefore respondents from different parts of Slovakia were chosen for the survey. Secondly, we selected enterprises from the agricultural and food sector with a different orientation, focusing on their possible innovation capacity in terms of potential utilization of available knowledge from applied research, particularly in the field of agriculture and food industry. Finally, willingness to participate in the survey was the crucial aspect for receiving responses. We explained in detail to all contacted respondents the goals of the survey, as well as the importance of having good empirical data, and the way of practical usage of research findings in order to provide recommendations for policy and decision makers. In total, we contacted 330 agro-food subjects, from which 205 were represented by agricultural entities and 125 were represented by companies operating in food industry. From these, 107 respondents participated in the questionnaire survey. We had to remove 8 questionnaires which were not fully and correctly completed, so the final total drop to 99 agro-food enterprises.

Standard criteria for classifying company size according to the number of employees were used. Out of a total of 99 respondents, small enterprises with a number of employees between 10 and 49 represented the largest share of the sample (42\%). This category of enterprises was followed by a category of microenterprises (31\%) with a number of employees between 1 and 9 , and by a category of medium-sized enterprises (24\%, 
employing between 50 and 249 workers). The smallest share (3\%) in the sample consisted of large companies with 250 or more employees. The largest proportion of selected the companies (74\%) was among companies with a period of operation in the time range from 1 to 5 years, the rest of them have been operating longer. Locally operating enterprises represented $37 \%$ in the total sample, followed by regionally operating enterprises (29\%). Companies that operated across borders and in national scope were represented almost equivalently (18 and $16 \%)$. Majority of the agricultural and food entities involved in the questionnaire survey had a domestic owner of the holding (94\%), while only a minority of respondents reported the foreign ownership or the fact that it is a branch or a subsidiary of a foreign company. Concerning the economic sector and business orientation, the largest proportion of agricultural companies were engaged in mixed economic activities (i.e., plant production and animal husbandry). The second most numerous group were companies oriented at planting activities (25\%), followed by enterprises aimed at food production (12\%). We also recorded enterprises engaged in animal husbandry and beverage production. The lowest share of respondents was represented by the companies operating in the fishing industry and aquaculture.

The most homogeneous subsample, from the point of view of the size of the enterprises, consisted of small enterprises with local territorial scope. Microenterprises declared their representation in all categories according to the territorial competence. The most often indicated territorial scope of microenterprises was a locality, followed by a region, and their smallest share was represented in the category of enterprises with national and international scope of activity. Small enterprises, like microenterprises, declared the largest representation in the category of entities with local and regional activities and the smallest in the category of subjects with national and international activities. Medium-sized enterprises were almost equally represented in each of these categories. Large companies declared international activities. Assessment of the sample of respondents, based on a combination of business size criterion with an economic sector, confirmed that the most heterogeneous part of the total sample was the sample of small enterprises targeting plant cultivation, animal husbandry, mixed farming, food and drink production, as well as fishery and aquaculture. Microenterprises focused their economic activities on planting, animal husbandry, mixed production, food and drink production. Medium-sized enterprises operated in the area of plant cultivation, mixed farming, food production, beverage production, and fisheries and aquaculture. Large enterprises operated in planting, mixed farming and food production.

\section{Procedure}

This survey followed required ethical principles of conducting empirical data in social sciences research. The researchers took all necessary steps to protect the privacy and confidentiality of the responded subjects. All respondents indicated their informed consent for participation in the survey.

At the beginning of the survey, respondents were contacted and informed about the research topic and about the main aims of the survey. They were asked whether they are interested to take part in this survey. Respondents who agreed, and respondents who have not yet been definitively decided, were sent the questionnaire either online or via e-mail as an attached file according to their indicated preference. The full survey instrument was distributed in the Slovak language and was not translated to English. The questionnaire and the results were safety stored in Google Drive in a secure data center.

Before conducting the main survey, we ran a pre-test of the questionnaire with a small sample of respondents. Pre-tested sample was comprised of 35 enterprises, total $80 \%$ of them where agricultural enterprises and $20 \%$ were food producers, mainly small enterprises (employing up to 50 people). Pretesting process was realized using the method of standardized interview according the questionnaire. Based on the pretest survey results, we decided to slightly adapt formulation of few questions and expressions in the questionnaire. Pretesting procedure allowed us also to distinguish three different categories of responding companies within the sampleinnovative companies that collaborate with various subjects when developing their innovations; innovative companies that do not cooperate with other subjects but they are interested in doing so in the future; and companies without interest neither in cooperation nor in innovation. Similar findings demonstrated the study of Rogers (2003), according to which organizations can be classified as low-, medium-, or high-adopters. In general, classifications of innovators and innovation adopters, while meaningful for planning and descriptive purposes, need further empirical insights into whether there are strategies that can change companies from medium or low adopters to high adopters.

Questions in the questionnaire were divided into four basic thematic headings. First, respondents answered dichotomic and trichotomic questions about innovation planning and innovation strategy. They had also to answer open questions about key problems related to innovation in their company and to rate their attitudes to concrete barriers using 5-point differential scales. After that, they chose one or more offered answers to the polytomic question how innovations could positively influence the enterprise. Second, respondents completed series of mixed types of questions dedicated to bearers of innovative ideas, their experiences to date with cooperation with external institutions and stakeholders, and their future intentions and cooperation plans. In the section aimed at decision-making and implementation of innovation, respondents were asked to assess and identify both purposes for the implementation of innovations and factors hindering the uptake of innovation.

Next set of questions was oriented to concrete experiences with implementing innovations including types of innovations and financial sources. Respondents answered questions about how likely they were to use supporting mechanisms for improving their innovativeness, and if they need external sources for doing that on a 5-point Likert scale, ranging from certainly not to certainly yes. The fourth section of the questionnaire mapped the innovation governance and monitoring, and consisted of dichotomic and open questions about the management of innovation systems in companies, evaluation methods for innovation success or failure, and 
respondents' opinions on the strengths and weaknesses of innovation implementation. Finally, respondents were asked for basic enterprise information, including its size, duration of operation, territorial scope, nationality of the owner, and economic sector.

After obtaining the answers from the respondents, we created a basic data file based on the primary classification, and we prepared data for secondary classification. Data cleaning and analysis was conducted and after that we used standard mathematical and statistical methods for data processing (statistical classification, graphical display, numerical characteristics, descriptive statistics, hypothesis testing, etc.). In case the theoretical frequencies were lower than 5 we ran Fisher's exact test to determine whether there are statistically significant associations between different groups of responded enterprises (according to identifiers) and their responses. Kruskal-Wallis followed by Dunn's post-hoc test was used to evaluate significant differences between different groups of responded enterprises if responses were measured on an ordinal scale. We used the nonparametric Friedman test for testing matched sets to detect differences in multiple matched sets with numeric responses followed by Nemenyi's post-hoc method for pairwise evaluation.

\section{RESULTS AND DISCUSSION \\ Implementation of Innovations}

Many small firms in the agro-food sector, particularly in the EU, operate in a competitive globalized environment. New EU laws and regulations, fiercer international competition, and the growing presence of powerful players in the value chain partly explain the fact that large-scale production economics today influence the development of the agro-food sector in many EU countries. This combination of factors has increased the pressure on small and medium-sized agro-food firms to be more innovative (Brinkmann et al., 2014; Tell et al., 2016).

Innovation strategies in the agricultural and food sector need to respond to new challenges and strengthen economic development based on scientific knowledge in order to increase the companies' competitiveness. The results of the questionnaire survey showed that $46 \%$ of the respondents considered their business to be innovative, almost the same number of respondents $(44 \%)$ considered their enterprise to be partially innovative, and only a minimal number of respondents did not consider their business innovative. They, therefore, saw reserves in this respect, and they would appreciate the implementation of innovation in their enterprise. This was also indirectly confirmed by responses to collecting opinions on the possible contribution of innovation to the level of business competitiveness.

The majority of respondents, up to $77 \%$ of them, considered innovation as a key factor of increasing company's competitiveness. However, respondents also indicated that only $45 \%$ of responded companies disposed of an institutional innovation strategy. Although employees and management are aware of the importance of innovation for the operation and development of the company, they are not sufficiently active with respect to this topic. Almost half of those surveyed (46\%) reported that they do not allocate any resources for their own research, and only a small number of those interviewed (10\%) reported that they are not enough able to create these resources. This confirms that the most common problem for implementing innovation is the lack of funding and the quality of human potential. On the one hand, the responded companies do not have the necessary funding for their own research, on the other hand they do not use available external services in this field. Moreover, some of them have a negative attitude toward new ideas, products, processes, or technologies. As some authors pointed out, it is challenging to promote change in routine practice when decision-makers within organizations do not perceive changes as necessary (Garland et al., 2010). Other authors (Aarons et al., 2011; Wisdom et al., 2014) suggested that individuals in organizations may have difficulties knowing, weighing, or selecting appropriate innovations to solve particular problems, or their decision to adopt innovation is often complicated by organizational factors. As enterprises operate within both external and internal contexts, adoption of innovation can be influenced by organization characteristics, besides the operational size and structure, e.g. by its absorptive capacity, leadership and management style, quality of social capital, readiness for change, norms, culture, values, and social climate. However, the majority (94\%) of our respondents do not have neither a department for innovations and $\mathrm{R} \& \mathrm{D}$ nor a person responsible for managing innovation issues.

Approximately one third of the respondents (34.84\%) considered the company's internal resources (human capital) to be the main source for innovative ideas. These results are supported by several theoretical concepts that identify human capital as a key factor of innovativeness (Vanhaverbeke et al., 2012; Balog and Kol, 2013). According to the respondents, other drivers of innovative ideas were the customers and clients of the company and competing companies, what was identified by $17.21 \%$ and 13.11 respondents. Groups of suppliers, consulting companies, universities and research institutions, development centers, and professional associations were seen as an important source of innovative ideas, but not as much as human capital, clientele and competition.

Generally, innovations in agro-food sector involve much more than only technology. They regard also strategy, marketing, organization, management, and design. Innovative agro-food companies looking for alternatives to industrial agriculture do not necessarily implement and adopt only new technologies. Their novelties emerge as the outcome of different ways of thinking and novel approaches (Ploeg et al., 2004; Knickel et al., 2009). Our survey demonstrated that responded agrofood companies are lagging behind this trend. Up to 75\% of respondents said they had carried out innovations in the last 5 years. This was mainly technological innovation, which was mentioned by $33.52 \%$ of respondents. Product and service innovations were implemented by $26.14 \%$ of respondents including either new products or services, or improvements of existing products and services, and marketing and organizational process innovations were declared by $15.34 \%$ of respondents. From Figure 1, it can be noted that agro-food enterprises tend to deploy mainly technology innovations followed by product or service innovations rather than other types. When interviewed 


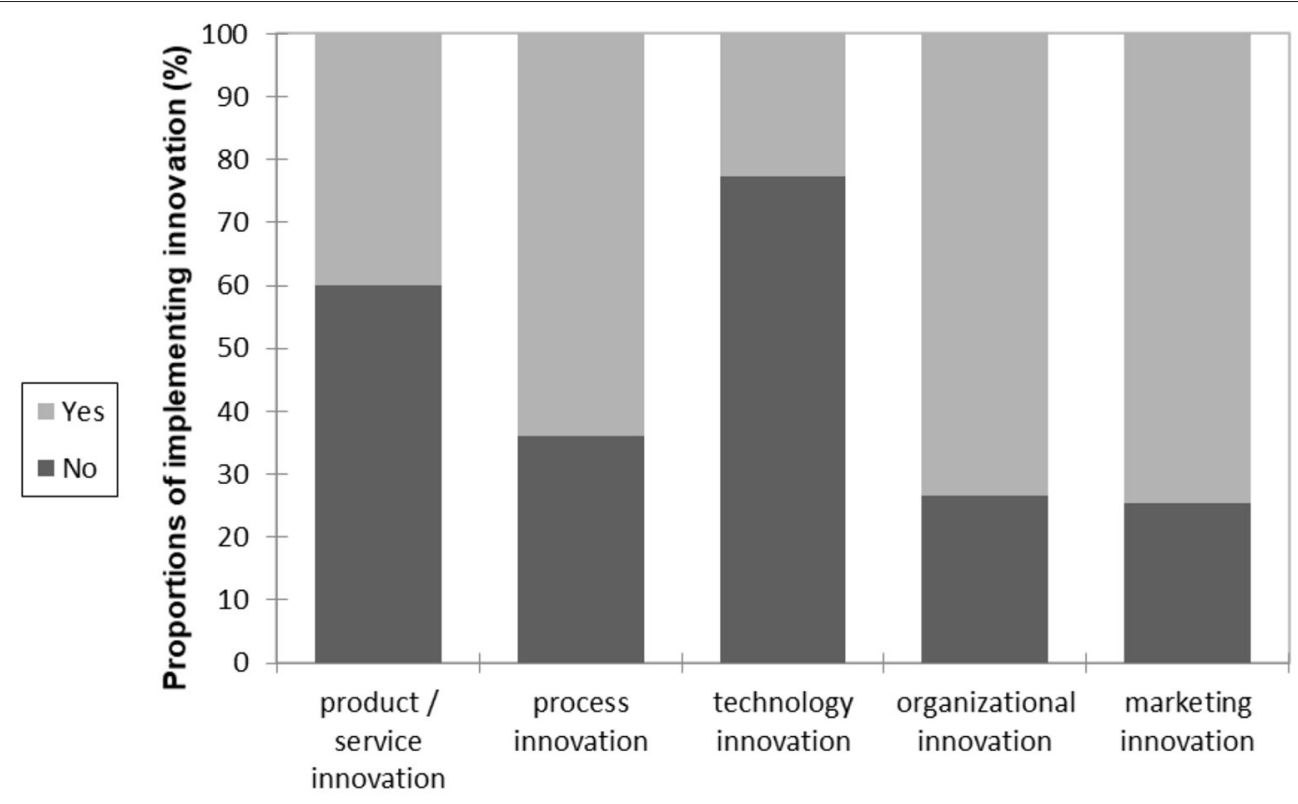

Type of innovation

FIGURE 1 | Innovation types implemented by enterprises.

about concrete examples of their innovations, respondents provided the following examples-e.g., purchase of machinery, modernization of technical equipment, new websites, new product composition, new labels and packaging, new varieties, new sowing practices, use of biotechnology etc. Results of the national survey realized by the Slovak Business Agency (2020) among SMEs also showed similar trends. Most often, businesses reported that they are engaged in product/service innovation and more than half of the companies surveyed were involved in the innovation process. Marketing innovations have been reported by less than $53 \%$ of businesses and less than $41 \%$ of those surveyed were involved in organizational innovation. At least, only slightly over $6 \%$ of respondents were engaged in innovations other than those mentioned above.

We ran Pearson's chi-squared test to determine whether there are statistically significant associations between different groups of responded enterprises (according identifiers) and their responses to the question about implementation of different types of innovations. Then we used the nonparametric Cochrane's Q test for testing matched sets in order to detect differences in multiple matched sets with binary (dichotomous) responses, and Sheskin's method to evaluate specific differences as posthoc to Cochrane's Q test. These results showed a significant relationship between the implementation of different innovation types and identifier reflecting various territorial scope of enterprise activities, while a significant difference was confirmed by Cochran' Q test and Sheskin Critical Difference $(p<0.01)$. Internationally and nationally operating agro-food companies tend to innovate processes and marketing activities more likely than companies with smaller operation scope from the regional point of view (Chi-squared; $p<0.01$ ). A significant positive correlation was found also between the territorial scope of business operation and the ability of enterprises to manage various types of innovations.

\section{Factors and Barriers Influencing the Motivation to Innovate}

The reasons for introducing innovation represent an essential element in the decision-making process, or at all, why and how to innovate. The reasons for innovation should be clear and unambiguous for each business. Every company should also know its strengths and weaknesses, market demands and current trends, as well as its competition, which can help to answer the question of why to innovate. Results showed that $89 \%$ of respondents consider the improvement in product quality as the most important factor. Observed companies had a certain range of goods and services already placed on the market, but ensuring their sustainability or increasing consumption requires some changes. Another essential factor for $86 \%$ of respondents is the need to optimize the company's costs and increase the company's competitiveness (85\%). Three-quarters of the businesses contacted considered the expansion of products or services to be an important and very important factor. On the contrary, the existing legislation was not confirmed by respondents as an important reason for introducing innovation.

On the other side, the vast majority of respondents (91\%) confirmed that the biggest problem in introducing innovation is the lack of funding. While agro-food businesses recognize the need to innovate, they are struggling with a lack of funding. This is related to the second most frequently mentioned factor preventing innovation-cost optimization, which was reported 
TABLE 1 | Barriers to innovation.

\begin{tabular}{|c|c|c|c|c|c|c|c|c|}
\hline & Mean of ranks & & & & & & & \\
\hline Reluctance of universities and research institutions & 3.950 & A & & & & & & \\
\hline Lack of partners & 4.350 & A & B & & & & & \\
\hline Lack of information about infrastructure of universities & 4.450 & A & B & & & & & \\
\hline Problematic cooperation with partners & 4.725 & A & B & C & & & & \\
\hline Lack of experience in managing innovation & 5.520 & & B & C & D & & & \\
\hline Lack of qualified staff & 6.985 & & & & $\mathrm{D}$ & E & $\mathrm{F}$ & \\
\hline Bureaucracy & 7.435 & & & & & E & $\mathrm{F}$ & G \\
\hline High expenses & 8.175 & & & & & & $\mathrm{~F}$ & G \\
\hline Lack of financial resources & 8.510 & & & & & & & G \\
\hline
\end{tabular}

by up to $88 \%$ of those contacted. A deficiency of skilled workers followed, particularly in the agricultural sector. In this sector, job choices are influenced by labor intensity, seasonality of work, low pay, and a high average age of employees. Thus $76 \%$ of respondents considered this indicator to be significant and very significant problem factor. Bureaucracy, especially in relation to the process of administration of projects funded from the European structural funds, was indicated by $73 \%$ of respondents as very important problem in the process of innovation. Lack of information on innovation and innovation opportunities were reported by 58 and $60 \%$ of respondents. Agro-food businesses considered as a significant barrier to innovation also a lack of experience in managing innovation (50\%). Regarding the issue of cooperation between universities and scientific research institutions and the business sector, or regarding reluctance to cooperate, almost half of the respondents were not able to assess this factor. About one third of enterprises have also identified a lack of partners for business cooperation or problematic cooperation among the faced problems in the innovation process. Approximately the same proportion of respondents took a neutral position. In addition to these facts, respondents identified other problems impeding innovation, such as insufficient support from the state and corruption.

As it was mentioned above, fundamental factor that influences the fact whether a company wants or can introduce innovations is the existence of specific obstacles that prevent this process. We found that the biggest obstacles (Table 1) are the lack of funds, high costs, and bureaucracy (Friedman test; $p<$ 0.01). We believe that the solution to this problem could be to increase transparency and streamline grant and other support schemes while simplifying their acquisition, especially in terms of administrative complexity concerning less experienced potential beneficiaries, i.e., smaller and newly established entities, respectively. According to results of national survey among the Slovak small and medium-sized firms (Slovak Business Agency, 2020), in all regions of Slovakia, the barrier related to the lack of funding for innovative activities came to the first place, too. Funding for innovation is often risky, making external financing even more difficult and appears to be a very serious innovation barrier, especially in small and medium-sized firms, whose resources are in many cases extremely limited. Other barriers reported by respondents included, for example, too high innovation costs, difficulties in obtaining state subsidies or innovation grants, too high or too low market competition, lack of cooperation partners, lack of good ideas, and a shortage of skilled employees.

Another key problem of agro-food companies in Slovakia is related to the low level of their willingness to cooperate within the sector and to create and/or to join networks. As some empirical researches has shown, the agro-food entrepreneurs who have developed a more specialized managerial outlook usually have adopted new business models based on the network approach. According to Brinkmann et al. (2014), the network approach allows agro-food firms to overcome their size-related disadvantages while still retaining the advantages of small producer independency. Moreover, these agro-food networks, with their focus on environmental sustainability and community involvement, support the position of the individual entrepreneurs as integrated members of society. Business models based in such value systems can contribute to agro-food firms' long-term profitability.

In addition to removing barriers, it is necessary to increase the motivation (Table 2) of agro-food enterprises to innovate their production. Expanding the offer of goods and services, improving their quality, optimizing costs and possible growth of competitiveness were perceived by respondents as motivation factors at the same level (Friedman test; $p<0.01$ ). Contrary the existing legislation, we can consider the least motivating element in the field of introducing innovations, which creates space, especially for policymakers to increase the interest of entrepreneurs in the innovative modernization of their business.

Often, however, there is a gap between the need for change and agro-food entrepreneurs' willingness to adjust, and the insufficient capacities of innovation agencies and advisory services to effectively support changes. There are various kinds of gaps between present societal demands, the related companylevel adjustments, and the capacities of innovation agencies and advisory services (Knickel et al., 2009). Slovak small and mediumsized firms have significant shortcomings in the implementation of business innovations, not only from the internal point of 
TABLE 2 | Factors influencing the motivation to innovate.

\begin{tabular}{lcc}
\hline & Mean of ranks & Groups \\
\hline Existing legislation & 1.940 & $\mathrm{~A}$ \\
Expanding the range of goods and services & 2.875 & \\
Cost optimization & 3.260 & $\mathrm{~B}$ \\
Growth of competitiveness & 3.450 & $\mathrm{~B}$ \\
Improving product quality & 3.475 & $\mathrm{~B}$ \\
\hline
\end{tabular}

view but also with respect to the external environments. Apart from investing in innovation to a limited extent, they also pay insufficient attention to new trends in digitization and R\&D activities. The Slovak small and medium-sized firms low level of innovativeness is also influenced by a qualitatively subdivided education system and low-value jobs, which is reflected in the lack or exit of qualified professionals. As in the case of the $\mathrm{EU}$, there is considerable fragmentation in the introduction of innovations in Slovakia. Despite the adoption of several initiatives aimed at improving the innovation activity of small and medium-sized firms, it should be noted that they did not increase the innovation performance of small and medium-sized firms and the issue of innovation continues to be one of the most problematic areas of Slovak small and medium-sized firms in general.

\section{Utilization of Financial Sources for Innovation Support}

Financing innovation activities is an important challenge for many firms including agro-food companies. Each enterprise may use different financial sources and tools to fund their innovation activities reflecting individual possibilities and opportunities. While some firms can use internal sources to fund their innovation activities, many have no option but to raise funding from external sources. Several external financial sources might be considered, e.g., bank loans, venture capital, state budget resources in the form of grant or project schemes and programs, as well as funds from the Structural Funds of the European Union. The technological and market uncertainty of innovation activities makes the returns to investment highly uncertain, creating significant problems for the standard risk assessment methods.

Sources of funding innovations could be considered as a crucial factor influencing possibilities to innovate (not only) in the category of agro-food companies. Table 3 shows structural funds from the European Union as an essential part of financing innovation in the case of Slovakia supplemented by mainly own resources and funds from the state budget, while bank loans and venture capital are not so popular (Friedman test; $p<0.01)$. It follows from the above that Slovak agro-food entrepreneurs are not willing to use borrowed resources to finance innovation. We can assume that the financing of innovation, still in our conditions, represents a kind of bonus, for which either surplus financial resources or resources obtained from support mechanisms are used. It is understandable that due to the limitations of support from the EU Structural Funds, these are slightly less used by international companies (KruskalWallis, $p<0.01$ ). In contrast, bank loans are less used by local enterprises (Kruskal-Wallis, $p=0.02$ ) and enterprises under 5 years of age (Kruskal-Wallis, $p<0.01$ ), which results from the general parameters of lending by banks in Slovakia. Respondents of the national survey (Slovak Business Agency, 2020) saw similar barriers to financing innovation activities - lack of own resources (34\% of respondents), and timeconsuming administration of national and/or EU funds (28.5\% of responded entrepreneurs). However, only a negligible proportion of these respondents $(0.7 \%)$ said that they considered the reluctance of banks to lend and lack of interest to investors as a barrier for financing innovative activities. Furthermore, no barrier to fund innovation activities was recorded by $6.3 \%$ of respondents.

Besides financial support, an indispensable part of innovation management is also information support and the creation of partnerships both between companies and between companies and public sector institutions. The innovation can be based on the investment in scientific applied research realized at universities or research institutions and on the number of patents. It is very often associated with high-tech products and $\mathrm{R} \& \mathrm{D}$ activities mostly carried in urban areas. Most of agro-food firms, particularly small and medium-sized firms, lack this possibility and opportunity. The intensity of the innovation activity of enterprises is mostly influenced by the level of their legal awareness and by the ability to utilize the innovation mechanisms and opportunities for transfer of knowledge, modern technologies and practices (Moravčíková et al., 2017). While the exchange of information between entities, advisory in the area of EU funds, and preparation of innovative projects are the most used possibilities to enhance the innovation potential of Slovak agro-food companies, we can see a lack of interest in financing legal advice about protection of intellectual property, international cooperation and research cooperation with academic sector (Table 4; Friedman test; $p<0.01)$. On the other hand, international companies took better care about intellectual property protection than others (Fisher; $p=0.01$ ). Additionally, we found out, that young ( $<5$ years) businesses tended to prepare innovation projects to a lesser extent than old ( $>10$ years) businesses (Kruskal-Wallis, $p=0.03$ ).

In the field of innovation, Slovakia has long been ranked below the EU average and lags behind the EU28 average in 8 out of 10 evaluated areas (European Commission, 2020). The worst position was in the area of financing and support (26th place), a favorable innovation environment (25th place), and intellectual assets (25th place) (European Commission, 2020). There are several important challenges of designing the innovation systems for the twenty-first century that are different in comparison to the previous period, e.g., in terms of the changed position of the public sector and the new structure of actors, such as private research institutions, advisory services, as well as civic organizations. 
TABLE 3 | Importance and utilization of different financial sources for innovations.

\begin{tabular}{|c|c|c|c|c|}
\hline \multirow[b]{2}{*}{ Venture capital } & \multirow{2}{*}{$\begin{array}{c}\text { Mean of ranks } \\
1.46\end{array}$} & \multicolumn{3}{|c|}{ Groups (Nemenyii; $p<0.05$ corr.) } \\
\hline & & A & & \\
\hline Bank loans & 2.90 & & $\mathrm{~B}$ & \\
\hline Funds from the state budget & 3.26 & & $\mathrm{~B}$ & C \\
\hline Own resources & 3.69 & & & C \\
\hline Resources from the EU structural funds & 3.71 & & & $\mathrm{C}$ \\
\hline
\end{tabular}

TABLE 4 | Importance of utilization of external financial sources to boost innovations.

\begin{tabular}{|c|c|c|c|c|c|}
\hline \multirow[b]{2}{*}{ Intellectual property protection (legal advice) } & \multicolumn{2}{|l|}{ Mean of ranks } & \multicolumn{3}{|c|}{ Groups (Nemenyii; $p<0.05$ corr.) } \\
\hline & 3.71 & A & & & \\
\hline Membership in international partnerships and networks & 4.16 & A & $\mathrm{B}$ & & \\
\hline Joint/custom research with universities & 4.36 & A & $\mathrm{B}$ & & \\
\hline Innovative training and workshops & 4.95 & & $\mathrm{~B}$ & C & \\
\hline Membership in domestic partnerships and networks & 5.08 & & $\mathrm{~B}$ & C & \\
\hline Advice on creating a business plan & 5.14 & & $\mathrm{~B}$ & C & \\
\hline Preparation of innovative projects & 5.26 & & $\mathrm{~B}$ & $\mathrm{C}$ & $\mathrm{D}$ \\
\hline Advice on the use of EU funds & 5.93 & & & C & $\mathrm{D}$ \\
\hline Exchange of information with other entities & 6.43 & & & & D \\
\hline
\end{tabular}

\section{Management and Monitoring of Innovations}

According to our respondents, selected enterprises do not have an innovation management system that is directly linked to the innovation strategies of their enterprises. This was confirmed by a majority of respondents (75\%). We also asked them about if they use information and communication technologies to support and manage innovation, but up to $58 \%$ reported they were not using them. Responses of respondents pointed to one of the crucial innovation weaknesses of agro-food businesses in Slovakia that might be caused by skill shortages, older age, and lower education level of employees, which, in particular in the agricultural sector, have long been confirmed as a problem by national statistical data, too.

Only $27 \%$ of the respondents confirmed that they manage the agenda of intellectual property rights protection. On the contrary, many respondents stated that they had neither considered protecting intellectual property (54\%) nor claimed their existence (19\%). Many of them do not have any knowledge about these issues, and many of them had only very low level of awareness toward these issues. However, some respondents declared that their companies address the intellectual property protection agenda. Such enterprises can be classified as innovative companies, as the area of intellectual property protection is managed by entities that innovate but also follow new trends, adapt to turbulent market conditions, and seek to be more competitive. Respondents also confirmed by their statements in the open question that the area of intellectual property and its protection do not belong to the companies' strengths. The research results are in line with the general situation in Slovakia, which is typical by a very low level of awareness, mainly among small and medium-sized firms, about the importance of intellectual property protection.

Each company may have a different perspective and different metrics to assess the success of innovation. Many companies consider innovations that increase the company's turnover and profit to be successful, while the others also include qualitative indicators for measuring success rates, for example in terms of expressed added value of innovation. Furthermore, increasing company's competitiveness through the expansion on markets or increased number of clients and customers, or high-quality human capital, are also often defined among the success factors in innovation assessment. Less than half of the companies in our sample evaluated the success of their innovations (44\%). The rest of the respondents (56\%) have not yet addressed the creation of an innovation assessment system. Respondents, as factors for assessing the success of innovation, reported in particular lower costs, higher profit, the overall economic performance of the company, feedback from customers and clients, return on investment, increase in the number of new customers, improvement of customer satisfaction with products and services, results of economic analyses and increased self-competitiveness on the market. Respondents also answered the question whether they had experience with failed innovations. From a total number of 99 respondents, $32 \%$ of them replied positively. According to their responses, changes in legislation, changes in markets, and bureaucracy were the most common reasons for the failure of innovation.

We used statistical methods (Procedure section) to find out possible correlations between enterprises' identifiers and the existence of some methods or systems for assessing the success of innovation. The results demonstrated that there are 


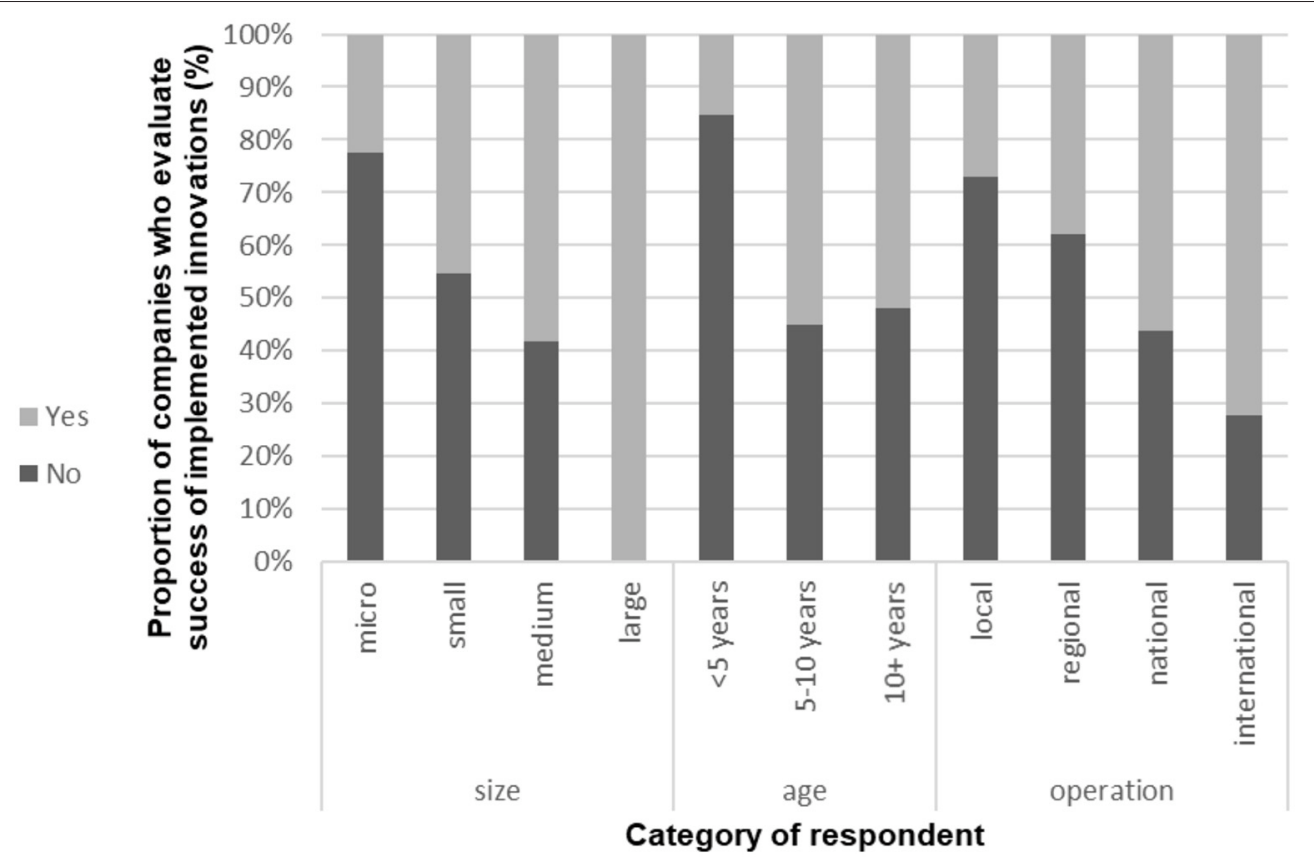

FIGURE 2 | Evaluation of successful innovations.

differences in the existence of measurement and evaluation of the success of the implemented innovations (Figure 2), while there is a positive relationship between size, age as well as operation area of the company (Fisher; $p<0.01$ ). International companies also tended to itemize unsuccessful innovations more than other types (Fisher; $p<0.01$ ), while it can be explained by a strong positive relationship $(\Phi=$ $0.42 ; p<0.01$ ) between whether companies evaluate the success of implemented innovations and the existence of unsuccessful innovations.

The final open questions in the questionnaire were oriented toward assessing the strengths and weaknesses that respondents consider essential regarding innovation. The main strengths indicated by the interviewed representatives of agro-food companies were following: cost savings, increased sales, development of the company, increased competitiveness, business dynamism and growth, market expansion, new customers, simpler production, higher productivity, lower personnel costs, better working environment and conditions (including animal welfare). On the other side, increased costs, low return on investment, inefficiency of innovation process, high cost of innovation, time constraints, financial risks, lack of feedback, difficulties in implementing innovation, the need for lifelong learning, disruption of established conditions, and a stress factor were among the most often identified weaknesses.

\section{CONCLUSION}

This study demonstrates selected aspects and key determinants which affect the motivation of the Slovak agro-food companies to innovate as well as the processes of implementation, and management and monitoring of innovation. The findings point out that substantial changes will be required in regulation and support of innovations in the agro-food sector, at both national policy and regional policy levels in Slovakia.

To point out scientific shortcomings and limitations, future research in the agro-food sector would benefit from further development of its theoretical foundations, and particularly with respect to the many small and medium-sized firms in the EU, more attention should be given to how such firms can use innovative business models to compete in world markets (Tell et al., 2016). According to the opinion of researchers reviewing theories and concepts on innovation adoption (Wisdom et al., 2014), many theoretical frameworks seek to describe the dynamic process of the implementation of innovations. However, a lack of precise definitions and measurement of constructs suggests further work is needed to increase a deeper understanding of the adoption of innovations. There is a room for more future research aiming at comparison of the potential for innovativeness in the agro-food sector in different countries or regions. Several research studies emphasize the importance and role of agricultural innovation systems (Knickel et al., 2009; Klerkx and Rose, 2020). In order to shape future food systems, there is a key role for agricultural innovation systems that are concerned with the networks of actors from science, business, civil society, and government and that need to become mission-oriented. Institutions sometimes continue to provide certain types of support, while the needs of enterprises and of society have changed. More research is needed on the question of institutional arrangements and factors that support or hinder the diffusion and adoption of innovations, the role of organizations facilitating innovation as well as public innovation 
policies. Furthermore, existing studies have rarely engaged with issues such as directionality, power, and the diversity of food systems futures.

In our opinion, two-fold directions of future research could help better to understand the phenomenon of innovativeness in different external environment. Firstly, more qualitative research into the implementation, uses and effects of business model innovation from the company perspective is needed, and a deeper understanding of this topic should include also information from popular publications, sector magazines and national language publications. Secondly, larger quantitative studies in the EU countries and regions might consider using similar or the same survey instrument for better comparison and identification of differences and similarities. Future research could also address the way how legislation and policies (at European, national, and regional level) affect the innovation behavior of agro-food companies, and what role such regulations play in the decision

\section{REFERENCES}

Aarons, G. A., Hurlburt, M., and Horwitz, S. (2011). Advancing a conceptual model of evidence-based practice implementation in public service sectors. Admin. Policy Mental Health Mental Health Serv. Res. 38, 4-23. doi: $10.1007 / \mathrm{s} 10488-010-0327-7$

Balog, M., and Kol. (2013). Inovatívne Slovensko - východiská a výzvy. Bratislava: Slovenská inovačná a energetická agentúra.

Brinkmann, P., Håkansson, A., Butiene, I., Kjærsgard, H., Mortensen, B. K., Martens, J., et al. (2014). The use of networks as a strategic approach of micro-enterprises in the agri-food sector. Int. J. Entrep. Innov. 15, 169-178. doi: $10.5367 /$ ijei.2014.0156

Cappelli, A., Canessa, J., and Cini, E. (2020a). Effects of $\mathrm{CO}_{2}$ snow addition during kneading on thermoregulation, dough rheological properties, and bread characteristics: a focus on ancient and modern wheat cultivars. Int. J. Refrig. 117, 52-60. doi: 10.1016/j.jbiomech.2019.07.005

Cappelli, A., and Cini, E. (2021). Challenges and opportunities in wheat flour, pasta, bread, and bakery product production chains: a systematic review of innovations and improvement strategies to increase sustainability, productivity, and product quality. Sustainability 13:2608. doi: $10.3390 /$ sul3052608

Cappelli, A., Mugnaini, M., and Cini, E. (2020b). Improving roller milling technology using the break, sizing, and reduction systems for flour differentiation. LWT Food Sci. Technol. 133, 110067. doi: 10.1016/j.lwt.2020.110067

Cappelli, A., Parretti, C., Cini, E., and Citti, P. (2019). Development of a new washing machine in olive oil extraction plant: a first application of usabilitybased approach. J. Agric. Eng. 50, 134-142. doi: 10.4081/jae.2019.949

Cavicchi, A., and Stancova, K. C. (2016). Food and Gastronomy as Elements of Regional Innovation Strategies. Spain: European Commission, Joint Research Centre, Institute for Prospective Technological Studies.

Christensen, J. L. (2008). "Knowledge sourcing for product innovation in the food and drinks industry," in Handbook of Innovation in the Food and Drink Industry, eds R. Rama (Devon: Food Product Press), 297-322.

Corchuelo Martínez-Azúa, B., López-Salazar, P.E., and Sama-Berrocal, C. (2020). Determining factors of innovative performance: case studies in extremaduran agri-food companies. Sustainability 12:9098. doi: 10.3390/su12219098

Drucker, P. (1985). Innovation and Entrepreneurship: Practice and Principles. New York, NY: Harper Collins Publishers.

European Commission (2007). Economic analysis of EU agriculture: the importance and contribution of the agri-food sector to the sustainable development of rural areas. DEV-RU 27295, European Commission, Directorate-General for Agriculture and Rural Development, Brussels, 3 September. making of agro-food company managers about "why, what and how" to innovate.

\section{DATA AVAILABILITY STATEMENT}

The raw data supporting the conclusions of this article will be made available by the authors, without undue reservation.

\section{AUTHOR CONTRIBUTIONS}

DM contributed to the conception and design of the study. DM and FT wrote sections of the manuscript, while DM ensured the completion of the content and prepared the final version. FT performed the statistical analysis. FT and KM wrote a draft dedicated to the interpretation of statistical analysis results. All authors contributed to manuscript revision, read, and approved the submitted version.
European Commission (2020). European Innovation Scoreboard 2019. Online. Available online at: https://op.europa.eu/en/publication-detail/-/publication/ d156a01b-9307-11e9-9369-01aa75ed71a1/language-en/format-PDF/source136061387 (accessed May 05, 2021).

Fáziková, M., and Mariš, M. (2010). Znalostná ekonomika a polnohospodárstvo v Nitrianskom kraji. National and Regional Economics VIII. Slovenská polnohospodárska univerzita v Nitre: Innovation Policy platform. Available online at: https://innovationpolicyplatform.org/content/agriculture?topicfilters=11399 (accessed May 05, 2021).

Finco, A., Bentivoglio, D., and Bucci, G. (2018). Lessons of Innovation in the Agrofood Sector: drivers of innovativeness performances. Econ. Agro-aliment. 20, 181-192. doi: 10.3280/ECAG2018-002004

Food Drink Europe (2020). Data and Trends of the European Food and Drink Industry 2020. Available online at: https://www.fooddrinkeurope.eu/resource/ data-trends-of-the- european-food-and-drink-industry-2020/ (accessed May 05, 2021).

Garland, A., Bickman, L., and Chorpita, B. (2010). Change what? Identifying quality improvement targets by investigating usual mental health care. Admin. Policy Mental Health Mental Health Serv. Res. 37, 15-26. doi: 10.1007/s10488-010-0279-y

Hirsch, S., and Gschwandtner, A. (2013). Profit persistence in the food industry: evidence from five European countries. Eur. Rev. Agric. Econ. 40, 741-759. doi: $10.1093 / \mathrm{erae} / \mathrm{jbt} 007$

Jongen, W. M. F., and Meulenberg, M.T.G. (2005). Innovations in AgroFood Systems. 2nd ed. Wageningen: Wageningen Academic Publisher. doi: 10.3920/978-90-8686-666-3

Klerkx, L., and Rose, D. (2020). Dealing with the game-changing technologies of agriculture 4.0: how do we manage diversity and responsibility in food system transition pathways? Global. Food Secur. 24:100347. doi: 10.1016/j.gfs.2019.100347

Knickel, K., Brunori, G., Rand, S., and Proost, J. (2009). Towards a better conceptual framework for innovation processes in agriculture and rural development: from linear models to systemic approaches. J. Agric. Educ. Exten. 15, 131-146. doi: 10.1080/13892240902 909064

Maciborski, D., Olko, D., Palczewska, M., Patorska, J., Szewczyk, P., and Wałachowski, W. (2021). Food Foresight: Impact of COVID-19 on the agri-food sector in Central and Eastern Europe. EIT Food Hub. Available online at: https:// www.eitfood.eu/food-foresight (accessed May 05, 2021).

Moravčíková, D., Ilková, Z., and Štefeková, P. (2017). Legal and financial instruments supporting the innovation and technology transfer. EU Agrar. Law 6, 18-28. doi: 10.1515/eual-2017-0003

National Agricultural and Food Centre Slovakia Research Institute of Agricultural and Food Economics (2021). Report on Agriculture and Food Sector in the 
Slovak Republic 2019-Green Report. Available online at: https://www.mpsr.sk/ en/index.php?navID=16andid=76 (accessed May 05, 2021).

OECD/EUROSTAT (2018). Oslo Manual 2018: Guidelines for Collecting, Reporting and Using Data on Innovation. 4th Edition. The Measurement of Scientific, Technological and Innovation Activities. Paris/Eurostat, Luxembourg: OECD Publishing.

Pittner, M., and Švejda, P. (2004). Rízení inovací v podniku. Praha: Asociace inovačního podnikání CR.

Ploeg, J. D., Bouma, J., Rip, A., Rijkenberg, F. H. J., Ventura, F., and Wiskerke, J. S. C. (2004). "On regimes, novelties and co-production," in Seeds of Transition, eds J. S. C. Wiskerke and J. D. Ploeg van der. Van Gorcum: Assen.

Rogers, E. M. (2003). Diffusion of innovations (5th ed.). New York, NY: Free Press.

Slovak Business Agency (2020). Inovačný potenciál MSP na Slovensku. SBA: Bratislava.

Statistical Office of the Slovak Republic (2018). Inovačná aktivita podnikov $v$ Slovenskej republike 2014 - 2016. Available online at: https://slovak. statistics.sk/wps/wcm/connect/252f80f5-0daf-49c5-b315-15a296e69dad/ Inovacna_aktivita_podnikov_v_Slovenskej_republike_2014_2016.pdf?MOD= AJPERES\&CACHEID=ROOTWORKSPACE-252f80f5-0daf-49c5-b31515a296e69dad-munA5VE (accessed May 05, 2021).

Tell, J., Hoveskog, M., Ulvenblad, P., Ulvenblad, P.O., Barth, H., and Ståhl, J. (2016). Business Model Innovation in the Agri-food Sector. Int. J. Soc. Ecol. Sustain. Dev. 7, 1-13. doi: 10.4018/IJSESD.2016040101

Vanhaverbeke, W., Vermeersch, I., and De Zutter, S. (2012). Open Innovation in SMEs: How Can Small Companies and Start-Ups Benefit From Open Innovation Strategies. Research Report.

Vanhonacker, F., Kühne, B., Gellynck, X., Guerrero, L., Hersleth, M., and Verbeke, W. (2013). Innovations in traditional foods: Impact on perceived traditional character and consumer acceptance. Food Res. Int. 54, 1828e1835. doi: 10.1016/j.foodres.2013.10.027

Wisdom, J.P., Chor, K.H., Hoagwood, K.E., and Horwitz, S.M. (2014). Innovation adoption: a review of theories and constructs. Adm. Policy Mental Health 41, 480-502. doi: 10.1007/s10488-013-0486-4

Zouaghi, F., and Sánchez,. M. (2016). Has the global financial crisis had different effects on innovation performance in the agri-food sector by comparison to the rest of the economy? Trends Food Sci. Technol. 50, 230-242. doi: 10.1016/j.tifs.2016.01.014

Conflict of Interest: The authors declare that the research was conducted in the absence of any commercial or financial relationships that could be construed as a potential conflict of interest.

Publisher's Note: All claims expressed in this article are solely those of the authors and do not necessarily represent those of their affiliated organizations, or those of the publisher, the editors and the reviewers. Any product that may be evaluated in this article, or claim that may be made by its manufacturer, is not guaranteed or endorsed by the publisher.

Copyright () 2021 Moravčíková, Tkáč and Mušinská. This is an open-access article distributed under the terms of the Creative Commons Attribution License (CC BY). The use, distribution or reproduction in other forums is permitted, provided the original author(s) and the copyright owner(s) are credited and that the original publication in this journal is cited, in accordance with accepted academic practice. No use, distribution or reproduction is permitted which does not comply with these terms. 